\title{
Editorial for the special issue: integrated assessment model analysis of climate change in China
}

\author{
Yi-Ming Wei ${ }^{1} \cdot$ Biying Yu ${ }^{1}$ \\ Published online: 7 November 2019 \\ (c) Springer Nature B.V. 2019
}

Climate change is one of the biggest risks of our time for human society. Anticipating the future under the climate change and identifying effective climate mitigation strategies are very challenging tasks. Integrated assessment model (IAM) is the mainstream methodological approach in climate change research. IAMs simulate the complex relations between earth, social and economic systems that determine future climate change, and they require input from atmospheric scientists, oceanographers, ecologists, economists, policy analysts, and others. China has become the world's largest carbon dioxide emitter as from 2017. This special issue on Integrated Assessment Model Analysis of Climate Change in China focuses on the current state of knowledge about the effects of climate change on natural and socioeconomic systems in China and how to mitigate or adapt to climate change; meanwhile with particular emphasis on how to narrow down the uncertainty of possible outcomes caused by IAM methods and so many climate-sensitive factors, such as energy technology innovation, land use transformation, socioeconomic development, domestic and international market fluctuation, earth system evolution, and so on.

Four papers focus on past and future impacts of climate change and techniques that researchers are using to study them. Yuan and Sun investigate the potential human damage and economic losses in China from weather-related events (including rainfall-related events, drought events and cold-related events) under future climate conditions explained by representative concentration pathways (RCPs). Considering the climate change has led to significant temperature rise, Zhang et al. profile an effort to estimate the changes in electricity consumption due to temperature fluctuation resulted from climate change at the county scale in rural China. Xie et al. use a global computable general economic model to assess the role of the domestic market and international trade on food production under extreme drought and heat due to climate change. Zang et al. simulate the influence of the urbanization on hydrological processes under different precipitation conditions and land use scenarios, which are likely to occur with climate change.

Two papers try to draw a picture of the pathway for achieving the short-, mid- and longterm climate mitigation targets. Jiang et al. explore the required energy transition pathway for achieving the long-term global $2{ }^{\circ} \mathrm{C}$ and $1.5^{\circ} \mathrm{C}$ targets and meanwhile meeting the targets of air pollutants reduction and energy security in China, based on the IPAC model. Regarding

Biying Yu

yubiying_bj@bit.edu.cn

1 Center for Energy and Environmental Policy Research, Beijing Institute of Technology, Beijing, China 
the short- and mid-term Nationally Determined Contributions target, Wu et al. adopt a computable general equilibrium model to investigate the impacts of achieving Taiwan's NDC target under the emission trading scenario and under cap without trade scenario.

The earth system is one of the core parts of IAMs. However, traditional complex earth system models used in natural sciences cannot match the integrated assessment models well due to differences in temporal and spatial resolutions and especially computational complexities. Liu et al. develop a simple earth system model called BCC_SESM which describes the basic and complete processes including carbon cycle processes in atmosphere-land-ocean, the radiation forcing, and temperature changes.

Considering accurate accounting for carbon emissions is the premise for climate change analysis, three papers work on how to provide more reliable estimations and understanding on emissions through improving the techniques, decomposing the detailed process and identifying the driving forces. Chen et al. propose a method called the emission accounting model to overcome the shortcomings of poor data availability and the incomplete consideration of the fuel consumption process, and re-estimate the $\mathrm{CO}_{2}$ emissions in China's chemical industry. Wang et al. provide a more accurate accounting for the carbon emissions during coal development process from the original source. Xiao et al. examine the degree of influence held by the energy consumption structure and other factors over carbon emission intensity and the spatial spillover effect to further link with the future carbon emissions amount.

Domestic and international markets play an important role in responding to climate change but with very large uncertainty. Two papers discuss the potential influence of domestic and international market on carbon emissions. Oil is an essential and important energy source for China. Concerned with the uncertain effectiveness of climate change mitigation caused by fluctuation of international oil market, Xue et al. investigate the socioeconomic impacts of oil shortage. Ji et al. shed light on the carbon emissions trading scheme, which is one of the most promising way to mitigate the carbon emissions, and claim that carbon price fluctuation, unsound price mechanism, and carbon pricing policy are the main disturbances and research focus for the launch of carbon trading market.

Currently, fossil fuel consumption and industrial process emissions contribute more than $65 \%$ to the anthropogenic GHG emissions. To dig into the uncertainty of total demand for energy fuels, Yu et al. offer a snapshot of China's energy consumption in the past, present, and future to facilitate the understanding of what has happened, the main cause and what is likely coming in the future, which can help prepare for the potential climate change. Targeting the uncertainty of population distribution, Jiang et al. compare energy consumption by rural migrant workers and urban residents with a hukou and the driving factors in China to see the likely impact of large-scale population migration on the climate change. Turning to the uncertainty of technology innovation from the energy-intensive sectors including thermal power, steel, cement, and coal chemical industries, Wang et al. analyze the impact of promoting advanced technologies on reducing the energy and emissions in China based on the developed $\mathrm{C}^{3}$ IAM-Tice model.

Finally, we would like to express our deepest thanks to the former Editor-in-Chief Tadepalli S. Murty for inviting us to prepare and edit this special issue. He was a highly intelligent and forward-looking scholar. He believed that climate change is one of the most challenging phenomena that human society is facing. He provided a lot of support for this special issue. We deeply mourn over the passing of Prof. Murty.

Publisher's Note Springer Nature remains neutral with regard to jurisdictional claims in published maps and institutional affiliations. 